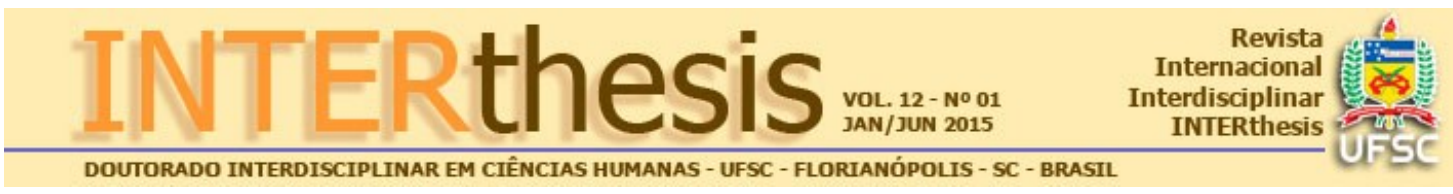

\title{
DISTRIBUIÇÃO ESPACIAL DA DESIGUALDADE DE GÊNERO NO BRASIL
}

\author{
Patrícia Verônica Pinheiro Sales Lima ${ }^{1}$ \\ Marina Rocha de Sousa ${ }^{2}$ \\ Ahmad Saeed Khan ${ }^{3}$ \\ Leonardo Andrade Rocha ${ }^{4}$
}

\section{Resumo:}

$\mathrm{O}$ artigo tem como objetivo analisar como a desigualdade de gênero encontra-se distribuída entre as unidades federativas do Brasil. Para tanto, optou-se pela construção de um índice sintético nomeado de Índice Multidimensional de Desigualdade de Gênero (IMDG). Os principais resultados apontaram que a desigualdade entre homens e mulheres se manifesta com diferentes graus nas unidades federativas, mas é determinada por fatores comuns. As assimetrias são observadas, principalmente, nas dimensões política, trabalho e renda.

Palavras-chave: Desigualdade de gênero. Índice sintético. Análise multidimensional. Unidades federativas. Políticas públicas.

\section{INTRODUÇÃO}

A busca por uma equidade de direitos entre mulheres e homens é uma aspiração mundial e encontra-se materializada em iniciativas como a Declaração Universal dos Direitos Humanos (1948), a Convenção sobre a Eliminação de Todas as Formas de Discriminação Contra a Mulher - CEDAW (1979), a Agenda 2, elaborada durante a Rio 92 (1992), a Quarta Conferência Mundial sobre a Mulher que originou a Plataforma de Ação de Pequim (1995) entre outras. O compromisso pela redução das desigualdades de gênero é, também, um dos objetivos do milênio: Objetivo 3 - Promover a igualdade entre os sexos e a autonomia das mulheres, além de ser tratado de forma transversal em todos os demais (sete objetivos).

\footnotetext{
${ }_{1}^{1}$ Doutora em Economia Aplicada pela Universidade de São Paulo, Escola Superior de Agricultura Luis de Queiroz. Professora da Universidade Federal do Ceará, Fortaleza, CE, Brasil. Bolsista de Produtividade CNPq. E-mail: pvpslima@gmail.com

2 Estudante de Agronomia da Universidade Federal do Ceará, Fortaleza, CE, Brasil. Email: marina rochadesousa@ymail.com

${ }^{3}$ Doutor em Economia Agrícola e Recursos Naturais pela Oregon State University, EUA. Professor da Universidade Federal do Ceará, Fortaleza, CE, Brasil. Bolsista de Produtividade - CNPq. E-mail: saeed@ufc.br

${ }^{4}$ Doutor em Desenvolvimento Economico pelo Instituto de Economia da Universidade Estadual de Campinas, Campinas, SP, Brasil. Professor Adjunto da Universidade Federal Rural do Semi-Árido, Mossoró, RN, Brasil. E-mail: leonardoandrocha@yahoo.com.br
} 
Ainda na perspectiva de redução de desigualdade entre homens e mulheres, em 2011 foi formalizada a Entidade das Nações Unidas para a Igualdade de Gênero e o Empoderamento das Mulheres, na busca por acelerar o progresso e o atendimento das demandas de mulheres e meninas em todo o mundo. Mais recentemente, durante a Primeira Cúpula de Mulheres Chefes de Estado e de Governo ocorrida na Rio +20 em julho de 2012, foi debatida a necessidade de políticas e acordos para eliminar as barreiras discriminatórias que contribuem para intensificar as desvantagens da mulher frente aos homens.

No Brasil, "a Constituição Federal de 1988 simboliza um marco fundamental na instituição da cidadania e dos direitos humanos das mulheres" (Alves e Correa, 2009. p.14) deixando claro no Art.3, IV - "constituem objetivos fundamentais da República Federativa do Brasil: [...] promover o bem de todos, sem preconceitos de origem, raça, sexo, cor, idade e quaisquer outras formas de discriminação" e Art. $5^{\circ}$, I - "homens e mulheres são iguais em direitos e obrigações, nos termos desta Constituição".

Para Vianna e Unbehaum (2004) foi a constituição que melhor representou os interesses dos movimentos das mulheres distribuídos em todo território nacional e do Conselho Nacional dos Direitos da Mulher - CNDM. De fato, um exame no texto permite identificar a incorporação de temas ligados ao trabalho (Art. $7^{\circ}, \mathrm{XVIII}, \mathrm{XX}$ e XXX), propriedade da terra (Art. $189^{\circ}$ ), previdência social (Art. $202^{\circ}, \mathrm{I}$ ), família (Art. $226^{\circ}, \S 5 .^{\circ}$ ) e violência doméstica (Art. $226^{\circ}, \S 8 .^{\circ}$ ) na perspectiva da mulher (Costa,1998), embora de forma transversal, sem uma menção explícita à palavra gênero, dado que não era um termo usual à época da elaboração do documento.

Simultaneamente aos avanços legais, o país obteve ganhos socioeconômicos incontestáveis desde a década de 1980. O processo histórico que favoreceu uma série de transformações nos direitos das cidadãs e dos cidadãos, também contribuiu para a melhoria de muitos indicadores socioeconômicos o que levou à redução da desigualdade de gênero na educação e saúde, conforme relatório do Fórum Econômico Mundial (World Economic Forum, 2014). No entanto, segundo índices internacionais, o Brasil ainda apresenta elevados níveis de desigualdade entre homens e mulheres. É o caso do Gender Inequality Index (Índice de Desigualdade de Gênero) que coloca o Brasil na $85^{a}$ posição, em uma classificação que envolve 187 países, dados de 2013 (PNUD, 2014) e do Global Gender Gap Index (Índice 
Global de Desigualdade de Gênero - IGDP) que coloca o país na $82^{a}$ posição, em uma classificação que envolve 142 países. De acordo com o IGDP, os principais fatores que contribuíram para o fraco desempenho relativo brasileiro foram Empoderamento Político e Participação Econômica e Oportunidade, dimensões nas quais foram alcançados os escores 0,148 e 0,649, respectivamente (World Economic Forum, 2014).

Os dados apresentados descrevem uma realidade captada em nível nacional e podem orientar decisões tomadas na escala do governo federal. Contudo, a agregação dos dados em escala nacional pode levar a generalizações que não representam adequadamente as necessidades específicas das unidades federativas brasileiras. Diante dessa possibilidade o artigo analisa como a desigualdade de gênero se distribui nas unidades federativas brasileiras. Especificamente pretendese hierarquizar as unidades federativas brasileiras segundo o nível de desigualdade de gênero e identificar em quais dimensões ocorrem as maiores desigualdades entre mulheres e homens. Estudos dessa natureza adquirem relevância por favorecer a produção de informações necessárias aos processos de tomada de decisão que envolvem a interação entre governos federais e estaduais. Estes processos se acentuaram com a descentralização ocorrida no país, após a promulgação da Constituição Federal de 1988, a qual conferiu novas competências às unidades federativas, dentre elas uma maior participação na elaboração e implementação de políticas públicas, inclusive no âmbito das questões de gênero (Farah, 2004).

\section{DIFERENTES DIMENSÕES DA DESIGUALDADE DE GÊNERO}

A aplicação de técnicas quantitativas para mensurar aspectos subjetivos é um procedimento complexo e susceptível a críticas. Porém, tal procedimento vem sendo adotado de forma cada vez mais frequente nas Ciências Sociais, uma vez que permite uma análise estatística mais rigorosa a ser enriquecida com observações qualitativas.

R. Inter. Interdisc. INTERthesis, Florianópolis, v.12, n.1, p.292-320, Jan-Jun. 2015 
Exemplos emblemáticos nas análises voltadas para as desigualdades de gênero são o Global Gender Gap Index (Índice Global de Desigualdade de Gênero) ${ }^{5}$ elaborado pelo World Economic Forum (Fórum Econômico Mundial), o Women's Economic Opportunity Index (Índice de Oportunidade Econômica das Mulheres) calculado pela Economist Intelligence Unit (Unidade de Inteligência Econômica), o Social Institutions and Gender Index (índice de Gênero e Instituições Sociais) da Organisation for Economic Co-operation and Development (Organização para a Cooperação e Desenvolvimento Econômico) e o Gender Inequality Index (Índice de Desigualdade de Gênero) publicado pelo PNUD - Programa das Nações Unidas para o Desenvolvimento.

O Índice Global de Desigualdade de Gênero objetiva medir os:

[...] hiatos de gênero no acesso a recursos e oportunidades em cada país ao invés de níveis reais dos recursos disponíveis e oportunidades. Fazemos isso para tornar o Global Gender Gap Index independente dos níveis de desenvolvimento dos países. (World Economic Forum, 2011, p.3).

Neste contexto, Alves (2011) critica que o índice não capta a situação dos direitos econômicos, sociais e políticos das mulheres. O pesquisador acrescenta, ainda, que em países com enormes exclusões sociais, onde ambos os sexos são igualmente afetados por condições precárias de dignidade, não há diferenças entre homens e mulheres quanto à qualidade de vida, de modo que características socioeconômicas não podem ser classificadas como bons indicadores de gênero. Caso de países como Lesoto, Uganda, Namíbia e Burundi, que aparecem em posições superiores ao Brasil na classificação do índice. O Índice de Oportunidade Econômica das Mulheres é voltado para as oportunidades da mulher no mercado de trabalho e não contempla dimensões importantes da desigualdade de gênero como violência familiar, educação, acesso à política e renda. O Índice de Desigualdade de Gênero (IDG) do PNUD mede as desvantagens das mulheres em relação aos homens em três dimensões: saúde reprodutiva, empoderamento e atividade econômica (PNUD, 2011). Nesse sentido, busca contribuir para que sejam ou não percebidas as conquistas nessas dimensões, as quais representam aumento no potencial de desenvolvimento humano das mulheres, fazem parte de um caminho

5 O Índice Global de Desigualdade de Gênero mede as lacunas entre homens e mulheres em quatro áreas-chave: saúde, educação, economia e política. $O$ valor varia de varia entre 0 e 1 . Quanto mais próximo de 1 , maior a igualdade entre homens e mulheres.

R. Inter. Interdisc. INTERthesis, Florianópolis, v.12, n.1, p.292-320, Jan-Jun. 2015 
para melhorar a sua condição de vida e mobilidade social e, portanto, reduzem tensões sociais.

Os índices citados são alvo de críticas. O uso de índices sintéticos geralmente causa divisões (Freudenberg,2003; Nardo et al, 2005). Há que se reconhecer que nem todos os aspectos da desigualdade de gênero podem ser quantificados e expressos em um número, o que torna qualquer tentativa de representação dessa condição susceptível a críticas legítimas. Os céticos apontam riscos de omissão de indicadores relevantes, perda de informação decorrente da agregação, inconsistências metodológicas (Bérenger e Verdier-Chouchane, 2007). Por outro lado, o seu uso é sugerido quando se quer captar diferentes dimensões de um conceito multidimensional, as quais não podem ser reproduzidas por um único indicador (Mainali et al 2014). Além disso, índices sintéticos são úteis para avaliar o desempenho relativo de países, regiões, estados e municípios nas mais diferentes áreas, são fáceis de interpretar e, portanto, um bom subsídio na orientação de políticas públicas (Booysen, 2002; Böhringer e Jochem, 2006, Mosaner e Dowbor, 2014).

No contexto dos objetivos desta pesquisa, analisar as diferentes unidades da federação segundo fatores representativos da desigualdade entre mulheres e homens nas várias dimensões consideradas individualmente levaria a um trabalho hercúleo e sem objetividade. Assim, reconhecendo as vantagens e desvantagens do uso de índices sintéticos, acredita-se que o emprego dessa ferramenta metodológica se adequa ao presente estudo sem prejuízos ao rigor científico. Nessa perspectiva, adota-se como medida de desigualdade entre homens e mulheres nas unidades federativas brasileiras: o Índice Multidimensional de Desigualdade de Gênero (IMDG). Trata-se de uma proxy, pois seria um equívoco supor que a desigualdade entre homens e mulheres pode ser medida em toda sua abrangência.

O IMDG é composto por indicadores distribuídos em seis dimensões: educação, renda, trabalho, política, saúde reprodutiva e fatores de proteção (Quadro 1). A seleção dos indicadores adotou como critérios: i) a capacidade de capturar o tema de interesse, no caso as assimetrias entre homens e mulheres nas unidades federativas brasileiras, ii) fundamentação teórica ${ }^{6}$, iii) confiabilidade das fontes , iv)

${ }^{6}$ Foram consultadas referências como: Goldani (2000), Pinheiro et al (2002), Farah (2004), Saffioti (2004), Bruschini (2007), World Economic Forum, 2014.

R. Inter. Interdisc. INTERthesis, Florianópolis, v.12, n.1, p.292-320, Jan-Jun. 2015 
disponibilidade de dados para todas as unidades federativas e por sexo, condição esta necessária à metodologia de cálculo do índice, conforme será apresentado posteriormente. Esses critérios seguem as recomendações da literatura científica (Rigby et al. 2001; Booysen 2002; Jacobs e Goddard 2007).

Quadro 1. Indicadores adotados na construção do Índice Multidimensional de Desigualdade de Gênero (IMDG).

\begin{tabular}{|c|c|c|c|}
\hline Dimensão & Indicador $^{7}$ & Descrição ${ }^{8}$ & $\begin{array}{c}\text { Ano de } \\
\text { referência }\end{array}$ \\
\hline \multirow{4}{*}{ Educação } & $\begin{array}{l}l_{1}=\text { Taxa de alfabetização } \\
\text { das pessoas de } 10 \text { anos ou } \\
\text { mais de idade, por sexo }\end{array}$ & $\begin{array}{l}\text { Razão entre o total de pessoas de } 10 \\
\text { anos ou mais (homens ou mulheres), } \\
\text { alfabetizadas e o total de pessoas } \\
\text { (homens ou mulheres) nessa faixa } \\
\text { etária. Segundo o IBGE, a pessoa } \\
\text { alfabetizada é aquela que sabe ler e } \\
\text { escrever, independentemente dos } \\
\text { anos de estudo. }\end{array}$ & $\begin{array}{l}\text { IBGE - Censo } \\
\text { Demográfico, } \\
2010\end{array}$ \\
\hline & $\begin{array}{l}\text { le } 2=\text { Média de anos de } \\
\text { estudo das pessoas de } 15 \\
\text { anos ou mais de idade, por } \\
\text { sexo. }\end{array}$ & $\begin{array}{l}\text { Tempo médio de estudo de homens } \\
\text { ou mulheres com } 15 \text { anos ou mais de } \\
\text { idade. }\end{array}$ & $\begin{array}{l}\text { IBGE, } \\
\text { Pesquisa } \\
\text { Nacional por } \\
\text { Amostra de } \\
\text { Domicílios - } \\
2009\end{array}$ \\
\hline & $\begin{array}{l}\mathrm{le}_{3}=\text { Taxa de frequência } \\
\text { escolar de jovens de } 18 \text { a } \\
24 \text { anos de idade, por sexo. }\end{array}$ & $\begin{array}{l}\text { Razão entre o total de pessoas entre } \\
18 \text { e } 24 \text { anos (homens ou mulheres), } \\
\text { frequentando a escola e o total de } \\
\text { pessoas (homens ou mulheres) na } \\
\text { mesma faixa etária. }\end{array}$ & $\begin{array}{l}\text { IBGE - Censo } \\
\text { Demográfico, } \\
2010\end{array}$ \\
\hline & $\begin{array}{l}\text { le } e_{4}=\text { Proporção de Pessoas } \\
\text { de } 15 \text { anos ou mais de } \\
\text { idade com ensino superior } \\
\text { completo, por sexo. }\end{array}$ & $\begin{array}{l}\text { Razão entre as pessoas de } 15 \text { anos } \\
\text { ou mais de idade (homens ou } \\
\text { mulheres), com nivel superior } \\
\text { completo o o total de pessoas de } 15 \\
\text { anos ou mais de idade (homens ou } \\
\text { mulheres) em todos os níveis de } \\
\text { instrução. }\end{array}$ & $\begin{array}{l}\text { IBGE - Censo } \\
\text { Demográfico, } \\
2010\end{array}$ \\
\hline \multirow{3}{*}{ Renda } & $\begin{array}{l}\text { Ir } \mathrm{r}_{1}=\text { Proporção de pessoas } \\
\text { de } 10 \text { anos ou mais de } \\
\text { idade, ocupadas e não } \\
\text { remuneradas, por sexo. }\end{array}$ & $\begin{array}{l}\text { Razão entre o total de pessoas de } 10 \\
\text { anos ou mais de idade (homens ou } \\
\text { mulheres), ocupadas e não } \\
\text { remuneradas e o total de pessoas } \\
\text { (homens ou mulheres) ocupadas } \\
\text { nessa faixa etária }\end{array}$ & $\begin{array}{l}\text { IBGE - Censo } \\
\text { Demográfico, } \\
2010\end{array}$ \\
\hline & $\begin{array}{l}\mathrm{Ir} \mathrm{r}_{2}=\text { Proporção de pessoas } \\
\text { de } 10 \text { anos ou mais de } \\
\text { idade, ocupadas } \mathrm{e} \\
\text { recebendo mais de } 10 \\
\text { salários mínimos, por sexo. }\end{array}$ & $\begin{array}{l}\text { Razão entre o total de pessoas de } 10 \\
\text { anos ou mais de idade (homens ou } \\
\text { mulheres), ocupadas e recebendo } \\
\text { mais de } 10 \text { salários mínimos e o total } \\
\text { de pessoas (homens ou mulheres) } \\
\text { ocupadas nessa faixa etária. }\end{array}$ & $\begin{array}{l}\text { IBGE - Censo } \\
\text { Demográfico, } \\
2010\end{array}$ \\
\hline & $\operatorname{Ir} r_{3}=$ Índice de Gini da & Mede $\quad$ o grau de desigualdade & IBGE - Censo \\
\hline
\end{tabular}

${ }^{7}$ Cada indicador foi obtido separadamente para homens e mulheres.

${ }^{8}$ As "razões" foram calculadas tendo no denominador o total de homens no caso dos indicadores referentes ao sexo masculino ou o total de mulheres no caso dos indicadores referentes ao sexo feminino.

R. Inter. Interdisc. INTERthesis, Florianópolis, v.12, n.1, p.292-320, Jan-Jun. 2015 


\begin{tabular}{|c|c|c|c|}
\hline & \begin{tabular}{llr|} 
distribuição & do rendimento \\
nominal mensal das & messoas de 10 anos ou \\
pessoas & \\
mais de idade com \\
rendimento, por sexo.
\end{tabular} & $\begin{array}{l}\text { existente na distribuição de indivíduos } \\
\text { (homens ou mulheres) segundo a } \\
\text { renda domiciliar per capita. Seu valor } \\
\text { varia de 0, quando não há } \\
\text { desigualdade (a renda de todos os } \\
\text { indivíduos tem o mesmo valor), a } 1 \text {, } \\
\text { quando a desigualdade é máxima } \\
\text { (apenas um indivíduo detém toda a } \\
\text { renda da sociedade e a renda de } \\
\text { todos os outros indivíduos é nula). } \\
\end{array}$ & $\begin{array}{l}\text { Demográfico, } \\
2010\end{array}$ \\
\hline & $\begin{array}{l}\text { Ir } r_{4}=\text { Rendimento médio do } \\
\text { trabalho principal das } \\
\text { pessoas de } 16 \text { anos ou } \\
\text { mais de idade, ocupadas, } \\
\text { por sexo. }\end{array}$ & $\begin{array}{l}\text { Valor médio do rendimento recebido } \\
\text { por pessoas (homens ou mulheres), } \\
\text { com } 16 \text { anos ou mais, como } \\
\text { remuneração por sua atividade de } \\
\text { trabalho principal. }\end{array}$ & $\begin{array}{l}\text { IBGE - Censo } \\
\text { Demográfico, } \\
2010\end{array}$ \\
\hline \multirow{5}{*}{ Trabalho } & $\begin{array}{l}\text { It }_{1}=\text { Proporção de pessoas } \\
\text { de } 10 \text { anos ou mais de } \\
\text { idade, ocupadas e com } \\
\text { carteira assinada, por sexo. }\end{array}$ & $\begin{array}{l}\text { Razão entre o total de pessoas de } 10 \\
\text { anos ou mais de idade (homens ou } \\
\text { mulheres), ocupadas e com carteira } \\
\text { assinada e o total de pessoas } \\
\text { (homens ou mulheres) ocupadas } \\
\text { nessa faixa etária. }\end{array}$ & $\begin{array}{l}\text { IBGE - Censo } \\
\text { Demográfico, } \\
2010\end{array}$ \\
\hline & $\begin{array}{l}\text { It }{ }_{2}=\text { Proporção de pessoas } \\
\text { de } 10 \text { anos ou mais } \\
\text { idade, ocupadas } \\
\text { empregadoras, por sexo. }\end{array}$ & $\begin{array}{l}\text { Razão entre o total de pessoas de } 10 \\
\text { anos ou mais de idade (homens ou } \\
\text { mulheres), ocupadas e empregadoras } \\
\text { e o total de pessoas (homens ou } \\
\text { mulheres) ocupadas nessa faixa } \\
\text { etária. }\end{array}$ & $\begin{array}{l}\text { IBGE - Censo } \\
\text { Demográfico, } \\
2010\end{array}$ \\
\hline & $\begin{array}{l}\text { It }{ }_{3}=\text { Proporção de pessoas } \\
\text { de } 10 \text { anos ou mais de } \\
\text { idade e empregadas, por } \\
\text { sexo. }\end{array}$ & $\begin{array}{l}\text { Razão entre o número de } \\
\text { trabalhadores de } 10 \text { anos ou mais de } \\
\text { idade (homens ou mulheres), com } \\
\text { carteira de trabalho assinada, } \\
\text { inclusive os trabalhadores } \\
\text { domésticos, os militares e } \\
\text { funcionários públicos estatutários, } \\
\text { bem como os empregadores e } \\
\text { trabalhadores por conta própria que } \\
\text { contribuem para a previdência social, } \\
\text { e o total de pessoas (homens ou } \\
\text { mulheres) ocupadas nessa faixa } \\
\text { etária. }\end{array}$ & $\begin{array}{l}\text { IBGE - Censo } \\
\text { Demográfico, } \\
2010\end{array}$ \\
\hline & $\begin{array}{l}\text { It } 4 \text { Média de } \text { horas } \\
\text { semanais gastas } \\
\text { afazeres domésticos, por } \\
\text { sexo. }\end{array}$ & $\begin{array}{l}\text { Número médio de horas gastas em } \\
\text { afazeres domésticos, por semana, } \\
\text { entre pessoas de } 10 \text { anos ou mais de } \\
\text { idade (homens ou mulheres). }\end{array}$ & $\begin{array}{l}\text { IBGE, } \\
\text { Pesquisa } \\
\text { Nacional por } \\
\text { Amostra de } \\
\text { Domicílios, } \\
2009\end{array}$ \\
\hline & $\begin{array}{l}\text { It } 5 \text { = Média de horas } \\
\text { semanais habitualmente } \\
\text { trabalhadas, por sexo. }\end{array}$ & $\begin{array}{l}\text { Número médio de horas } \\
\text { habitualmente trabalhadas por } \\
\text { semana no trabalho principal das } \\
\text { pessoas de } 10 \text { anos ou mais de idade } \\
\text { (homens ou mulheres). }\end{array}$ & $\begin{array}{l}\text { IBGE - Censo } \\
\text { Demográfico, } \\
2010\end{array}$ \\
\hline \multirow[t]{2}{*}{ Política } & $\begin{array}{l}\text { lp } p_{1}=\text { Proporção de } \\
\text { deputados } \quad \text { estaduais, } \\
\text { segundo o sexo. }\end{array}$ & $\begin{array}{l}\text { Razão entre o número de mulheres } \\
\text { (ou homens) deputadas (ou } \\
\text { deputados) estaduais em relação ao } \\
\text { total de deputados e deputadas } \\
\text { estaduais. }\end{array}$ & $\begin{array}{l}\text { Tribunal } \\
\text { Superior } \\
\text { Eleitoral } \\
\text { (TSE), } 2010\end{array}$ \\
\hline & $\begin{array}{lrr}\text { lp2 }= & \text { Proporção } & \text { de } \\
\text { deputados } & \text { federais, }\end{array}$ & $\begin{array}{l}\text { Razão entre o número de mulheres } \\
\text { (ou homens) deputadas (ou }\end{array}$ & $\begin{array}{l}\text { Tribunal } \\
\text { Superior }\end{array}$ \\
\hline
\end{tabular}

R. Inter. Interdisc. INTERthesis, Florianópolis, v.12, n.1, p.292-320, Jan-Jun. 2015 


\begin{tabular}{|c|c|c|c|}
\hline & segundo o sexo. & $\begin{array}{l}\text { deputados) federais em relação total } \\
\text { de deputados e deputadas federais. }\end{array}$ & $\begin{array}{l}\text { Eleitoral } \\
\text { (TSE), } 2010\end{array}$ \\
\hline \multirow{2}{*}{$\begin{array}{c}\text { Saúde } \\
\text { Reprodutiva }^{9}\end{array}$} & $\begin{array}{l}\text { Is } 1 \text { Proporção de } \\
\text { adolescentes que tiveram } \\
\text { filho. }\end{array}$ & $\begin{array}{l}\text { Razão entre o número de } \\
\text { adolescentes entre } 15 \text { e } 19 \text { anos que } \\
\text { tiveram filho e o total de adolescentes } \\
\text { mulheres nessa faixa etária. }\end{array}$ & $\begin{array}{l}\text { IBGE - Censo } \\
\text { Demográfico, } \\
2010\end{array}$ \\
\hline & $\begin{array}{l}\text { Is } \mathrm{s}_{2}=\text { Taxa de } \\
\text { materna/1000 nalidade } \\
\text { vivos. }\end{array}$ & $\begin{array}{l}\text { Número de óbitos maternos a cada } \\
1000 \text { nascimentos. }\end{array}$ & $\begin{array}{l}\text { Datasus, } \\
2010\end{array}$ \\
\hline \multirow{2}{*}{$\begin{array}{l}\text { Fatores de } \\
\text { proteção }\end{array}$} & $\begin{array}{l}\text { Ifp } 1 \text { = Esperança de vida ao } \\
\text { nascer, por sexo. }\end{array}$ & $\begin{array}{l}\text { Número médio de anos que as } \\
\text { pessoas deverão viver a partir do } \\
\text { nascimento, se permanecerem } \\
\text { constantes, ao longo da vida, o nível } \\
\text { e o padrão de mortalidade por idade } \\
\text { prevalecentes no ano do Censo. }\end{array}$ & $\begin{array}{l}\text { IBGE, } \\
\text { Diretoria de } \\
\text { Pesquisas, } \\
\text { Coordenação } \\
\text { de } \\
\text { População e } \\
\text { Indicadores } \\
\text { Sociais, } 2010\end{array}$ \\
\hline & $\begin{array}{l}\text { Ifp } 2=\text { Proporção de pessoas } \\
\text { de } 10 \text { anos ou mais de } \\
\text { idade, ocupadas, que } \\
\text { contribuem para instituto de } \\
\text { previdência oficial no } \\
\text { trabalho principal, por sexo. }\end{array}$ & $\begin{array}{l}\text { Razão entre o total de pessoas } \\
\text { (homens ou mulheres) de } 10 \text { anos ou } \\
\text { mais de idade, ocupadas, que } \\
\text { contribuem para instituto de } \\
\text { previdência oficial no trabalho } \\
\text { principal e o total de pessoas } \\
\text { ocupadas (homens ou mulheres) } \\
\text { nessa faixa etária. }\end{array}$ & $\begin{array}{l}\text { IBGE - Censo } \\
\text { Demográfico, } \\
2010\end{array}$ \\
\hline
\end{tabular}

Fonte: Elaborado pelo autor

A estratégia metodológica empregada na construção do IMDG reproduz o mesmo procedimento matemático adotado pelo PNUD para o cálculo do IDG, sendo o ponto de diferença entre ambos, a inclusão de indicadores de renda, trabalho não remunerado e horas dedicadas aos afazeres domésticos, cuja ausência no IDG é apontada como uma de suas limitações (Klasen e Schüler,2011), e a adaptação de alguns indicadores conforme disponibidade e confiabilidade dos dados. As etapas seguidas no seu cálculo encontram-se sintetizadas na Figura $1^{10}$.

\footnotetext{
${ }^{9} \mathrm{Na}$ dimensão saúde são coletados apenas dados referentes ao gênero feminino. "Conforme PNUD essa dimensão não deve ser interpretada como uma média dos índices femininos e masculinos correspondentes, mas sim, como um ponto a meio caminho das normas estabelecidas para os indicadores de saúde reprodutiva - menos mortes maternais e menos gravidezes adolescentes" (PNUD,2011, p.172). A escolha dessa dimensão se justifica pelos pelos elevados índices de mortalidade materna e infantil no Brasil (Farah, 2004).

10 Detalhes da metodologia ver notas técnicas de PNUD (2014). Disponível em: http://hdr.undp.org/sites/default/files/hdr14 technical notes.pdf
} 
Figura 1. Etapas na construção do Índice Multidimensional de Desigualdade de Gênero (IMDG).

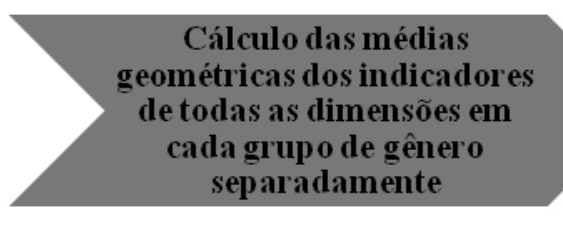

$>$

Agregação dos grupos de gênero, usando uma média harmônica
Agregação entre dimensões dentro de cada grupo de gênero, para tornar o IMDG sensivel à associação (consultar Seth, 2009).

Cálculo da média
geométrica das médias
aritméticas dos indicadores
de cada dimensão

Os indices feminino e masculino são agregados para criar o indice de gênero distribuído equitativamente. Este procedimento capta a desigualdade entre mulheres e homens e faz o ajustamento para a associação entre dimensões.

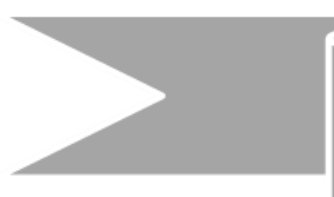

Cálculo do Índice Multidimensional de Desigualdade de Gênero (IMDG)

Fonte: Adaptado de PNUD (2011)

O cálculo das médias geométricas para homens e mulheres permitiu a agregação das seis dimensões e seguiu o procedimento:

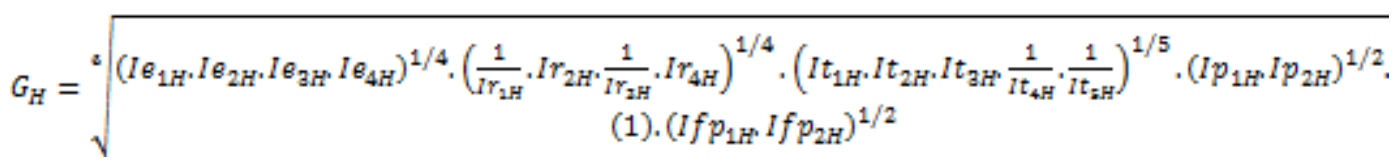

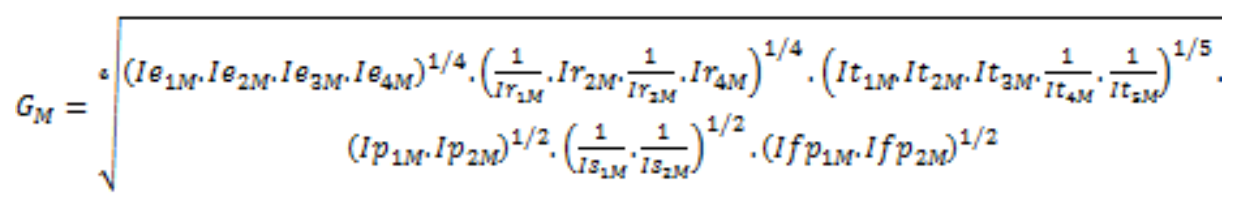

Sendo $G_{H}$ e $G_{M}$ a média geométrica para o grupo de homens e de mulhures, respectivamente. Entre parênteses, constam os indicadores de cada dimensão, conforme notação usada no quadro 1. A dimensão "saúde reprodutiva" é relevante apenas para o grupo de mulheres e recebe valor "um" no grupo de homens. Por fim, alguns indicadores são expressos em razão porque têm relação inversa com melhores condições de vida das mulheres.

A agregação dos grupos por média harmônica foi realizada a partir da equação:

R. Inter. Interdisc. INTERthesis, Florianópolis, v.12, n.1, p.292-320, Jan-Jun. 2015 


$$
\operatorname{HARM}\left(G_{H}, G_{M}\right)=\left[\frac{\left(G_{H}\right)^{-1}+\left(G_{M}\right)^{-1}}{2}\right]^{-1}
$$

Em seguida foi calculada a média geométrica da média aritmética de cada dimensão, agregando-se os dados de homens e mulheres:

$G_{\bar{H}, \bar{M}}=\sqrt[6]{\text { educação. }} \cdot \overline{\text { renda }} \cdot \overline{\text { trabalho }} \cdot \overline{\text { polítıca }} \cdot \overline{\text { saúde reprodutıva }} \cdot \overline{\text { fatores de proteção }}$

Sendo:

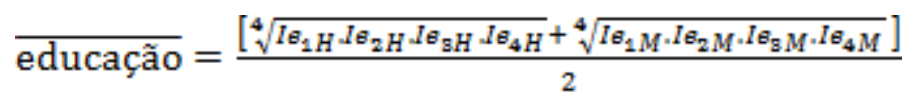

$\overline{\text { renda }}=\frac{\left[\sqrt[4]{\frac{1}{I r_{1 H}} \cdot I r_{2 H} \cdot \frac{1}{I r_{3 H}} \cdot I r_{4 H}}+\sqrt[4]{\frac{1}{I r_{1 M}} \cdot I r_{2 M} \cdot \frac{1}{I r_{3 M}} \cdot I r_{4 M}}\right]}{2}$

$\overline{\text { trabalho }}=\frac{\left[\sqrt[5]{I t_{1} H^{I} I t_{2 H} \cdot I t_{3} \cdot \frac{1}{I t_{4 H}} \cdot \frac{1}{I t_{5} H}}+\sqrt[5]{I t_{1 M} \cdot I t_{2 M} \cdot I t_{8 M} \cdot \frac{1}{I t_{4} M} \cdot \frac{1}{I t_{5} M}}\right]}{2}$

$\overline{\text { polítıca }}=\frac{\left[\sqrt{I p_{1 H} \cdot I p_{2 H}}+\sqrt{I p_{1 M} \cdot I p_{2 M}}\right]}{2}$

$\overline{\text { saúde reprodutiva }}=\frac{\left[1+\sqrt{\frac{1}{I s_{1} M} \cdot \frac{1}{I s_{2 M} M}}\right]}{2}$

$\overline{\text { fatores de produção }}=\frac{\left[\sqrt{\text { If } p_{1 H} \cdot \text { lf } p_{2 H}}+\sqrt{\text { If } p_{1 M} \cdot \text { If } p_{2 M}}\right]}{2}$

Por fim, o Índice Multidimensional de Desigualdade de Gênero (IMDG) foi obtido por:

$I M D G=1-\frac{\operatorname{HARM}\left(G_{H}, G_{M}\right)}{G_{H, M}}$

O IMDG varia de 0 a 1 e deve ser analisado de forma comparativa. Assim, quanto mais próximo de 1 , maior a desigualdade de gênero na unidade federativa analisada, considerando-se as dimensões avaliadas.

R. Inter. Interdisc. INTERthesis, Florianópolis, v.12, n.1, p.292-320, Jan-Jun. 2015 
Como todo índice sintético, o IDG e, em consequência, o IMDG, apresenta limitações como complexidade, dificuldade de interpretação, ausência de dimensões da desigualdade de gênero (Klasen and Schüler,2011; Permanyer, 2011). Porém, o seu uso como medida internacional e vantagens como i) identificar uma posição desigual das mulheres em relação aos homens ${ }^{11}$; ii) permitir a comparação entre as unidades federativas e iii) permitir a identificação das demandas de cada uma delas a partir da análise dos indicadores componentes de cada dimensão, tornam o seu emprego perfeitamente aceitável. Especificamente em relação ao IMDG ressalta-se o fato de captar os aspectos mais relevantes da desigualdade de gênero no Brasil e a inclusão de indicadores importantes na descrição da realidade brasileira, caso do trabalho não remunerado e horas dedicadas aos afazeres domésticos.

Contudo, é importante destacar que a construção do IMDG, em si, não é o objetivo do artigo, já que não se pretende discutir ou propor avanços metodológicos para mensuração da desigualdade entre homens e mulheres. Há o reconhecimento, no entanto, de que este é um campo de pesquisa que precisa se expandir e requer discussões mais amplas sobre inserção de indicadores e dimensões relevantes, ponderação, métodos de agregação. Essas discussões fogem ao escopo da pesquisa e só poderiam ser suficientemente aprofundadas em detrimento dos objetivos aqui propostos.

\section{AS MULTIDIMENSÕES DA DESIGUALDADE DE GÊNERO NO BRASIL}

O IMDG reflete aspectos importantes da desigualdade de gênero nas unidades federativas brasileiras. Porém, é importante ressaltar que a desigualdade de gênero a qual se refere $o$ índice diz respeito, naturalmente, somente às dimensões e, dentro destas, aos indicadores selecionados. Ademais, há a consciência de que os dados não falam por si e muitas vezes não captam a subjetividade inerente às questões de gênero. No entanto, é inconteste que a agregação dos indicadores pode permitir uma visão geral dos níveis de desigualdade entre mulheres e homens no território brasileiro e apontar áreas onde

\footnotetext{
11 O que é percebido quando o índice é diferente de zero, já que o seu valor, expresso em percentual, é interpretado como a perda percentual do potencial de desenvolvimento humano decorrente da desigualdade de gênero (PNUD, 2014).
}

R. Inter. Interdisc. INTERthesis, Florianópolis, v.12, n.1, p.292-320, Jan-Jun. 2015 
o problema se manifesta mais intensamente, o que favorece direcionamentos iniciais (prioridades) de intervenções voltadas para a promoção da igualdade entre os sexos.

A Tabela 1 apresenta as unidades federativas hierarquizadas segundo o valor do respectivo IMDG. É imperioso colocar que os valores absolutos não mensuram a desigualdade de gênero. São medidas relativas que permitem uma comparação entre unidades de observação. Assim, valores maiores significam que a unidade federativa tem maior nível de desigualdade em relação às demais, e não, que a intensidade da desigualdade é alta ou baixa.

Tabela 1. Índice Multidimensional de Desigualdade de Gênero (IMDG) nas unidades federativas do Brasil.

\begin{tabular}{lcr}
\hline \multicolumn{1}{c}{ Unidade da Federação } & $\begin{array}{c}\text { Índice Multidimensional de } \\
\text { Desigualdade de Gênero (IMDG) }\end{array}$ & Classificação \\
\hline Goiás & 0,1556 & 1 \\
Minas Gerais & 0,1300 & 2 \\
\hline Pernambuco & 0,1298 & 3 \\
Paraná & 0,1016 & 4 \\
Alagoas & 0,0976 & 5 \\
\hline Roraima & 0,0893 & 6 \\
São Paulo & 0,0859 & 7 \\
Espírito Santo & 0,0857 & 8 \\
Mato Grosso & 0,0833 & 9 \\
Bahia & 0,0821 & 10 \\
Maranhão & 0,0809 & 11 \\
\hline Santa Catarina & 0,0776 & 12 \\
Mato Grosso do Sul & 0,0771 & 13 \\
\hline Amazonas & 0,0763 & 14 \\
Rio Grande do Norte & 0,0762 & 15 \\
Rondônia & 0,0735 & 16 \\
Pará & 0,0689 & 17 \\
\hline Paraíba & 0,0682 & 18 \\
Ceará & 0,0648 & 19 \\
\hline Rio Grande do Sul & 0,0628 & 20 \\
Sergipe & 0,0625 & 21 \\
\hline Distrito Federal & 0,0608 & 22 \\
Tocantins & 0,0585 & 23 \\
Acre & 0,0565 & 24 \\
Rio de Janeiro & 0,0507 & 25 \\
Piauí & 0,0433 & 26 \\
Amapá & 0,0373 & 27 \\
\hline Font: Elabo &
\end{tabular}

Fonte: Elaborada pelos autores

A partir das informações expostas na Tabela 1 é possível observar: i) que as unidades federativas apresentam diferentes valores de IMDG (com exceção de 
Tocantins e Acre), ou seja, níveis distintos de desigualdade de gênero; ii) identificar onde o problema se manifesta com maior intensidade. Por exemplo, comparando-se Goiás (maior IMDG) e Amapá (menor IMDG) nota-se que a desigualdade de gênero, considerando-se as dimensões/indicadores avaliados, é 4,2 vezes maior em Goiás.

A análise da Tabela 1 permite inferir, ainda, que a desigualdade entre homens e mulheres no Brasil não tem caráter regional. Estados das regiões Sudeste, Centro Oeste e Nordeste estão entre os mais desiguais (Goiás, Minas Gerais e Pernambuco). No entanto, nessas regiões também estão as unidades federativas com menores assimetrias entre os sexos. Embora este não seja um resultado surpreendente, sugere que posições mais gerais como: "a região Nordeste apresenta maiores níveis de desigualdade entre homens e mulheres que a região Sudeste", merecem ressalvas.

O IMDG permitiu a hierarquização das unidades federativas e a percepção de que a distribuição espacial da desigualdade de gênero no Brasil não é uniforme. A caracterização de cada indicador componente do índice permitirá inferências sobre os fatores que mais contribuem para as assimetrias entre homens e mulheres nas unidades federativas. Optou-se por realizar tal caracterização pela razão Mulher/Homem de cada indicador ${ }^{12}$, dado que essa medida expressa a relação quantitativa entre o valor do indicador no grupo de mulheres e o seu valor no grupo de homens, evidenciando maiores discrepâncias entre os sexos à medida que se afasta da unidade. No caso de indicadores que contribuem positivamente para melhorar as oportunidades femininas, uma razão Mulher/Homem maior que 1 mostra uma situação favorável às mulheres. Por outro lado, se o indicador reduz as oportunidades, uma razão Mulher/Homem maior que 1 mostra uma situação desfavorável às mulheres. Em ambos os casos a unidade representa igualdade de condições entre os sexos. Considerou-se indicativo de diferença entre os sexos a razão Mulher/Homem menor ou igual a 0,95 e superior ou igual a 1,05 (o que corresponde a uma diferença de $\pm 5 \%$ no valor do indicador).

A Tabela 2 apresenta as razões Mulher/Homem correspondentes aos indicadores inseridos na dimensão "Educação". Todos os indicadores favorecem as oportunidades das mulheres. Portanto, valores maiores que 1 significam situação de

${ }^{12}$ Com exceção da dimensão saúde preventiva cujos indicadores se referem apenas às mulheres.

R. Inter. Interdisc. INTERthesis, Florianópolis, v.12, n.1, p.292-320, Jan-Jun. 2015 
vantagem para as mulheres. Como pode ser observado, não há diferenças significativas entre homens e mulheres quanto à taxa de alfabetização das pessoas com 10 anos ou mais de idade. Por outro lado, as maiores assimetrias verificadas nessa dimensão encontram-se na obtenção de diploma de curso superior, sendo que as mulheres são as mais favorecidas, comportamento observado em todas as unidades federativas. As maiores desigualdades nesse indicador foram identificadas no Maranhão, onde a proporção de mulheres com ensino superior supera a de homens em $76 \%$, e no Piauí onde a "vantagem" é de $74 \%$.

A taxa de frequência escolar de jovens entre 18 e 24 anos também é maior entre as mulheres na maioria das unidades federativas, especialmente no Rio Grande do Sul e Alagoas, com razões Mulher/Homem iguais a 1,36 e 1,33, respectivamente. Na maioria das unidades federativas a diferença entre mulheres $\mathrm{e}$ homens também é observada na média de anos de estudo. No entanto, nos estados das regiões Sul e Sudeste e no Distrito Federal não foram percebidas assimetrias significativas nesse indicador. Uma análise geral da dimensão aponta que a Educação não é um fator limitante das oportunidades das mulheres, pelo menos no contexto das análises de gênero. No entanto, alerta para a condição de vulnerabilidade dos homens.

Tabela 2. Razão Mulher/Homem dos indicadores adotados na construção do Índice Multidimensional de Desigualdade de Gênero (IMDG), dimensão educação, por Unidade Federativa.

\begin{tabular}{|c|c|c|c|c|}
\hline Unidade Federativa & $\begin{array}{lr}\text { Taxa } & \text { de } \\
\text { alfabetização das } \\
\text { pessoas de } 10 \\
\text { anos ou mais de } \\
\text { idade } \\
\end{array}$ & $\begin{array}{l}\text { Média de anos de } \\
\text { estudo das } \\
\text { pessoas de } 15 \\
\text { anos ou mais de } \\
\text { idade }\end{array}$ & \begin{tabular}{|lr}
$\begin{array}{l}\text { Taxa } \\
\text { frequência }\end{array}$ & de \\
escolar & de \\
jovens de & 18 a \\
24 anos de \\
\end{tabular} & $\begin{array}{lr}\text { Proporção de } \\
\text { Pessoas de } 15 \\
\text { anos ou mais de } \\
\text { idader com } \\
\text { ensino superior }\end{array}$ \\
\hline Acre & 1,03 & 1,10 & 1,20 & 1,58 \\
\hline Amazonas & 1,01 & 1,07 & 1,22 & 1,38 \\
\hline Amapá & 1,01 & 1,06 & 1,21 & 1,43 \\
\hline Pará & 1,03 & 1,13 & 0,98 & 1,43 \\
\hline Rondônia & 1,00 & 1,07 & 1,15 & 1,52 \\
\hline Roraima & 1,02 & 1,13 & 1,23 & 1,41 \\
\hline Tocantins & 1,02 & 1,15 & 1,25 & 1,54 \\
\hline Alagoas & 1,04 & 1,13 & 1,33 & 1,64 \\
\hline Bahia & 1,02 & 1,12 & 0,98 & 1,57 \\
\hline Ceará & 1,06 & 1,13 & 1,09 & 1,70 \\
\hline Maranhão & 1,05 & 1,14 & 1,14 & 1,76 \\
\hline Paraíba & 1,07 & 1,16 & 1,18 & 1,68 \\
\hline
\end{tabular}

R. Inter. Interdisc. INTERthesis, Florianópolis, v.12, n.1, p.292-320, Jan-Jun. 2015 


\begin{tabular}{l|r|r|r|r}
\hline Pernambuco & 1,03 & 1,10 & 1,03 & 1,62 \\
\hline Piauí & 1,06 & 1,21 & 1,08 & 1,74 \\
\hline Rio Grande do Norte & 1,08 & 1,11 & 1,13 & 1,59 \\
\hline Sergipe & 1,05 & 1,13 & 1,15 & 1,76 \\
\hline Distrito Federal & 1,00 & 1,02 & 1,03 & 1,21 \\
\hline Goiás & 1,00 & 1,08 & 1,28 & 1,54 \\
\hline Mato Grosso do Sul & 0,99 & 1,04 & 1,23 & 1,44 \\
\hline Mato Grosso & 1,00 & 1,07 & 1,23 & 1,49 \\
\hline Espírito Santo & 0,99 & 1,04 & 0,98 & 1,46 \\
\hline Minas Gerais & 0,99 & 1,04 & 1,21 & 1,54 \\
\hline Rio de Janeiro & 1,00 & 0,99 & 1,09 & 1,27 \\
\hline São Paulo & 0,99 & 0,99 & 1,09 & 1,25 \\
\hline Paraná & 0,98 & 1,01 & 1,21 & 1,38 \\
\hline Rio Grande do Sul & 1,00 & 1,03 & 1,36 & 1,51 \\
\hline Santa Catarina & 0,99 & 0,99 & 1,12 & 1,31 \\
\hline Font: Elarada pelo
\end{tabular}

Fonte: Elaborada pelos autores

A partir da literatura sobre gênero espera-se que a situação observada nas unidades federativas brasileiras, quanto ao acesso das mulheres à educação, crie um ambiente propício à redução das desigualdades em outras dimensões ${ }^{13}$, como por exemplo, a "renda". No entanto, ainda não se pode dizer que esses resultados esperados estejam, de fato, se concretizando. As razões Mulher/Homem expressas na Tabela 3 mostram as desigualdades de gênero nessa dimensão. Em negrito foram destacados os valores indicativos de diferença entre sexos, desfavoável ao grupo de mulheres, conforme limites estabelecidos anteriormente $( \pm 5 \%)$. Em termos de distribuição de renda, representada pelo ìndice de Gini, homens e mulheres se encontram em situação de igualdade. No entanto, o rendimento médio das mulheres é menor que o dos homens em todas as unidades federativas. A assimetria entre os sexos é ainda mais manifesta, se analizada a razão Mulher/Homem do indicador proporção de pessoas recebendo acima de 10 salários mínimos. Nos estados de Goiás, Tocantins, Rondônia e Espírito Santo o percentual de homens nessa faixa salarial supera o de mulheres em mais de $70 \%$. Outro fator de desigualdade nessa dimensão é a proporção de pessoas ocupadas e não remuneradas. No Distrito Federal e em Mato Grosso do Sul essa proporção no grupo das mulheres é mais que o dobro daquela verificada entre os homens. Por outro lado, o problema se

${ }^{13}$ Ver, por exemplo, os trabalhos de Hill e King (1995) e Ferrant (2010).

R. Inter. Interdisc. INTERthesis, Florianópolis, v.12, n.1, p.292-320, Jan-Jun. 2015 
manifesta de forma contrária nos estados do Ceará, Maranhão e Rio Grande do Norte, onde a proporção de homens nessa condição é maior que a de mulheres. Uma análise geral da tabela permite identificar que, em termos médios, o principal fator de desigualdade na dimensão renda é a proporção de pessoas de 10 anos ou mais de idade, ocupadas e recebendo mais de 10 salários mínimos.

Tabela 3. Razão Mulher/Homem dos indicadores adotados na construção do Índice Multidimensional de Desigualdade de Gênero (IMDG), dimensão renda, por Unidade Federativa.

\begin{tabular}{|c|c|c|c|c|}
\hline Unidade Federativa & $\begin{array}{l}\text { Proporção de } \\
\text { pessoas de } 10 \\
\text { anos ou mais de } \\
\text { idade, ocupadas e } \\
\text { não remuneradas }\end{array}$ & $\begin{array}{l}\text { Proporção de } \\
\text { pessoas de } 10 \\
\text { anos ou mais de } \\
\text { idade, ocupadas } \\
\text { e recebendo mais } \\
\text { de } 10 \text { salários } \\
\text { mínimos }\end{array}$ & $\begin{array}{l}\text { Índice de Gini } \\
\text { da distribuição } \\
\text { do rendimento } \\
\text { nominal mensal } \\
\text { das pessoas de } \\
10 \text { anos ou } \\
\text { mais de idade } \\
\text { com rendimento }\end{array}$ & $\begin{array}{l}\text { Rendimento } \\
\text { médio do } \\
\text { trabalho } \\
\text { principal das } \\
\text { pessoas de } 16 \\
\text { anos ou mais de } \\
\text { idade, ocupadas }\end{array}$ \\
\hline Acre & 1,50 & 0,73 & 0,98 & 0,85 \\
\hline Amazonas & 1,07 & 0,57 & 1,00 & 0,80 \\
\hline Amapá & 1,16 & 0,36 & 0,99 & 0,79 \\
\hline Pará & 1,23 & 0,44 & 1,01 & 0,75 \\
\hline Rondônia & 1,62 & 0,27 & 0,97 & 0,67 \\
\hline Roraima & 1,04 & 0,38 & 0,97 & 0,85 \\
\hline Tocantins & 1,46 & 0,29 & 0,97 & 0,78 \\
\hline Alagoas & 1,02 & 0,41 & 1,03 & 0,88 \\
\hline Bahia & 1,28 & 0,35 & 0,97 & 0,80 \\
\hline Ceará & 0,88 & 0,46 & 0,97 & 0,80 \\
\hline Maranhão & 0,79 & 0,43 & 0,99 & 0,70 \\
\hline Paraíba & 1,11 & 0,47 & 0,98 & 0,79 \\
\hline Pernambuco & 0,96 & 0,36 & 0,98 & 0,82 \\
\hline Piauí & 1,60 & 0,30 & 0,98 & 0,80 \\
\hline Rio Grande do Norte & 0,72 & 0,60 & 0,98 & 0,74 \\
\hline Sergipe & 1,37 & 0,56 & 0,98 & 0,77 \\
\hline Distrito Federal & 2,05 & 0,54 & 0,98 & 0,76 \\
\hline Goiás & 1,99 & 0,21 & 0,93 & 0,64 \\
\hline Mato Grosso do Sul & 2,52 & 0,33 & 0,95 & 0,60 \\
\hline Mato Grosso & 1,40 & 0,30 & 0,96 & 0,68 \\
\hline Espírito Santo & 1,84 & 0,28 & 0,93 & 0,69 \\
\hline Minas Gerais & 1,56 & 0,34 & 0,91 & 0,69 \\
\hline Rio de Janeiro & 1,26 & 0,48 & 0,96 & 0,68 \\
\hline São Paulo & 1,45 & 0,33 & 0,94 & 0,67 \\
\hline Paraná & 1,83 & 0,30 & 0,92 & 0,66 \\
\hline Rio Grande do Sul & 1,83 & 0,42 & 0,92 & 0,65 \\
\hline
\end{tabular}




\begin{tabular}{l|r|r|r|r}
\hline Santa Catarina & 1,73 & 0,33 & 0,90 & 0,64 \\
\hline Fonte: Elaborado pelo autor & & & &
\end{tabular}

Fonte: Elaborado pelo autor

$\mathrm{Na}$ Tabela 4 podem ser identificados os fatores determinantes das desigualdades de gênero na dimensão "Trabalho". Todos os indicadores analisados apresentam discrepância entre os sexos, sendo que esta é particularmente maior no indicador média de horas semanais gastas em afazeres domésticos, muito superior no grupo das mulheres. Mesmo que por questões culturais a respeito da mulher como a principal responsável pelas atividades do lar, esse fato pode interferir na condição das mulheres no mercado de trabalho. Uma análise de correlação reforça essa argumentação, ao apontar que quanto maior a razão Mulher/Homem da média de horas semanais gastas em afazeres domésticos, menores as razões Mulher/Homem dos indicadores média de horas semanais habitualmente trabalhadas e proporção de pessoas de 10 anos ou mais de idade e empregadas ${ }^{14}$. Essas relações são facilmente assimiláveis: nas unidades federativas onde as mulheres dedicam um maior número de horas às tarefas domésticas (relativamente às horas dedicadas pelos homens), a média de horas que as mulheres direcionam ao trabalho não doméstico é menor (se comparadas às horas dedicadas pelos homens). Da mesma forma, onde as mulheres dedicam um maior número de horas às tarefas domésticas (relativamente às horas dedicadas pelos homens), a proporção de mulheres empregadas é menor, se comparada à proporção de homens.

A proporção de mulheres de 10 anos ou mais de idade, ocupadas e com carteira assinada ainda é bem inferior, se comparada a dos homens, o que leva a suposições sobre a baixa participação das mulheres no mercado de trabalho e sobre a informalidade com que desempenham suas atividades geradoras de renda. As unidades federativas onde esse contexto parece ter maior ocorrência são Pará, Alagoas, Maranhão e Paraíba. O indicador proporção de pessoas de 10 anos ou mais de idade, ocupadas e empregadoras mostra outro ponto de desvantagem das

14 Coefiente de corelação de Pearson entre razão Mulher/Homem da média de horas semanais gastas em afazeres domésticos e razão Mulher/Homem da média de horas semanais habitualmente trabalhadas igual a -0,455, com nível de significância $=0,017$.

Coefiente de corelação de Pearson entre razão Mulher/Homem da média de horas semanais gastas em afazeres domésticos e razão Mulher/Homem da proporção de pessoas de 10 anos ou mais de de idade e empregadas igual a -0,559, com nível de significância =0,002.

R. Inter. Interdisc. INTERthesis, Florianópolis, v.12, n.1, p.292-320, Jan-Jun. 2015 
mulheres na dimensão trabalho. Essa proporção no grupo de homens é quase o dobro relativamente ao grupo de mulheres.

Tabela 4. Razão Mulher/Homem dos indicadores adotados na construção do Índice Multidimensional de Desigualdade de Gênero (IMDG), dimensão trabalho, por Unidade Federativa.

\begin{tabular}{|c|c|c|c|c|c|}
\hline Unidade Federativa & $\begin{array}{ll}\text { Proporção de } \\
\text { pessoas de } \\
10 \text { anos ou } \\
\text { mais } & \text { de } \\
\text { idade, } & \\
\text { ocupadas e } \\
\text { com carteira } \\
\text { assinada } \\
\end{array}$ & $\begin{array}{l}\text { Proporção de } \\
\text { pessoas de } \\
10 \text { anos ou } \\
\text { mais de de } \\
\text { idade, } \\
\text { ocupadas e } \\
\text { empregadoras }\end{array}$ & $\begin{array}{l}\text { Proporção } \\
\text { de pessoas } \\
\text { de } 10 \text { anos } \\
\text { ou mais de } \\
\text { de idade e } \\
\text { empregadas }\end{array}$ & $\begin{array}{l}\text { Média de } \\
\text { horas } \\
\text { semanais } \\
\text { gastas em } \\
\text { afazeres } \\
\text { domésticos }\end{array}$ & $\begin{array}{l}\text { Média de } \\
\text { horas } \\
\text { semanais } \\
\text { habitualmente } \\
\text { trabalhadas }\end{array}$ \\
\hline Acre & 0,61 & 0,48 & 0,98 & 2,22 & 0,79 \\
\hline Amazonas & 0,52 & 0,48 & 0,92 & 2,11 & 0,87 \\
\hline Amapá & 0,61 & 0,45 & 1,20 & 1,80 & 0,89 \\
\hline Pará & 0,39 & 0,42 & 0,87 & 2,55 & 0,79 \\
\hline Rondônia & 0,47 & 0,49 & 0,90 & 2,47 & 0,79 \\
\hline Roraima & 0,59 & 0,47 & 1,07 & 2,03 & 0,85 \\
\hline Tocantins & 0,40 & 0,44 & 0,94 & 2,61 & 0,72 \\
\hline Alagoas & 0,38 & 0,54 & 1,01 & 2,47 & 0,82 \\
\hline Bahia & 0,51 & 0,49 & 0,93 & 2,66 & 0,80 \\
\hline Ceará & 0,61 & 0,51 & 0,93 & 2,59 & 0,81 \\
\hline Maranhão & 0,39 & 0,48 & 0,95 & 2,47 & 0,81 \\
\hline Paraíba & 0,38 & 0,52 & 0,99 & 2,54 & 0,83 \\
\hline Pernambuco & 0,46 & 0,50 & 0,95 & 2,67 & 0,85 \\
\hline Piauí & 0,55 & 0,48 & 0,94 & 2,56 & 0,71 \\
\hline Rio Grande do Norte & 0,55 & 0,49 & 1,03 & 2,37 & 0,79 \\
\hline Sergipe & 0,50 & 0,51 & 0,92 & 2,75 & 0,82 \\
\hline Distrito Federal & 0,72 & 0,51 & 0,97 & 2,38 & 0,90 \\
\hline Goiás & 0,50 & 0,46 & 0,89 & 2,44 & 0,80 \\
\hline Mato Grosso do Sul & 0,54 & 0,43 & 0,81 & 2,55 & 0,78 \\
\hline Mato Grosso & 0,43 & 0,43 & 0,84 & 2,23 & 0,80 \\
\hline Espírito Santo & 0,53 & 0,47 & 0,85 & 2,55 & 0,81 \\
\hline Minas Gerais & 0,57 & 0,46 & 0,88 & 2,68 & 0,78 \\
\hline Rio de Janeiro & 0,57 & 0,50 & 0,87 & 2,23 & 0,86 \\
\hline São Paulo & 0,60 & 0,48 & 0,92 & 2,54 & 0,87 \\
\hline Paraná & 0,63 & 0,48 & 0,90 & 2,57 & 0,82 \\
\hline Rio Grande do Sul & 0,67 & 0,48 & 0,88 & 2,43 & 0,82 \\
\hline Santa Catarina & 0,69 & 0,51 & 0,90 & 2,49 & 0,86 \\
\hline
\end{tabular}

Fonte: Elaborada pelos autores 
A dimensão "Política" caracteriza-se como a mais desigual dentre as dimensões avaliadas. Segundo CEDIM (2002), apesar de possuírem níveis superiores de escolaridade, estarem inseridas na lutas e conquistas sociais, em nenhum âmbito da vida social a presença da mulher é tão desigual quanto na política. Os valores apresentados na Tabela 5 reforçam a condição desigual da mulher na política e corroboram a colocação de Piovesan (2011) a qual coloca que, embora as mulheres sejam mais da metade da população nacional, sua representatividade nos quadros dos Poderes Públicos está muito aquém dos $50 \%$. A lei de $\operatorname{cotas}^{15}$ como tentativa de aumentar o número de mulheres eleitas para exercer funções nos poderes executivo e legislativo não conseguiu desde a sua implementação, em 1996, alterar significativamente este fato de caráter histórico e cultural (Vaz, 2008; Miguel, 2000).

Conforme dados da IPU - Inter-Parlamentary Union, publicados em setembro de 2012, de um total de 190 países o Brasil ocupa a posição 119 quando se analisa o percentual nacional de cadeiras no parlamento ocupadas por mulheres. Em termos de unidades federativas Goiás, Minas Gerais e Pernambuco encontramse entre os mais desiguais nessa dimensão. Essa característica foi determinante para que atingissem os maiores IMDG entre todas as unidades federativas.

Tabela 5. Razão Mulher/Homem dos indicadores adotados na construção do Índice Multidimensional de Desigualdade de Gênero (IMDG), dimensão política, por Unidade Federativa.

\begin{tabular}{l|r|r}
\hline \multicolumn{1}{c|}{ Unidade Federativa } & $\begin{array}{c}\text { Proporção de deputados } \\
\text { estaduais }\end{array}$ & $\begin{array}{c}\text { Proporção de deputados } \\
\text { federais }\end{array}$ \\
\hline Acre & 0,20 & 0,28 \\
\hline Amazonas & 0,09 & 0,34 \\
\hline Amapá & 0,41 & 0,40 \\
\hline Pará & 0,21 & 0,23 \\
\hline Rondônia & 0,14 & 0,31 \\
\hline Roraima & 0,09 & 0,32 \\
\hline Tocantins & 0,20 & 0,33 \\
\hline Alagoas & 0,08 & 0,23 \\
\hline Bahia & 0,21 & 0,14 \\
\hline
\end{tabular}

15 Lei 9.100 de 29 de setembro de 1995, que estabelece normas para a realização das eleições municipais de 3 de outubro de 1996: "Cada partido ou coligação poderá registrar candidatos para a Câmara Municipal até cento e vinte por cento do número de lugares a preencher [...] $\S 3^{\circ}$ Vinte por cento, no mínimo, das vagas de cada partido ou coligação deverão ser preenchidas por candidaturas de mulheres" Art. 11, § $3^{\circ}$. (Brasil, 1996).

R. Inter. Interdisc. INTERthesis, Florianópolis, v.12, n.1, p.292-320, Jan-Jun. 2015 


\begin{tabular}{l|r|r}
\hline Ceará & 0,15 & 0,27 \\
\hline Maranhão & 0,20 & 0,14 \\
\hline Paraíba & 0,20 & 0,20 \\
\hline Pernambuco & 0,09 & 0,09 \\
\hline Piauí & 0,30 & 0,36 \\
\hline Rio Grande do Norte & 0,14 & 0,20 \\
\hline Sergipe & 0,33 & 0,15 \\
\hline Distrito Federal & 0,20 & 0,27 \\
\hline Goiás & 0,05 & 0,10 \\
\hline Mato Grosso do Sul & 0,09 & 0,49 \\
\hline Mato Grosso & 0,09 & 0,36 \\
\hline Espírito Santo & 0,15 & 0,20 \\
\hline Minas Gerais & 0,05 & 0,15 \\
\hline Rio de Janeiro & 0,23 & 0,32 \\
\hline São Paulo & 0,12 & 0,23 \\
\hline Paraná & 0,08 & 0,23 \\
\hline Rio Grande do Sul & 0,17 & 0,30 \\
\hline Santa Catarina & 0,11 & 0,34 \\
\hline
\end{tabular}

Fonte: Elaborada pelos autores

Como já mencionado, a dimensão saúde reprodutiva encontra-se caracterizada pelos indicadores taxa de moratlidade materna/1000 nascidos vivos e proporção de adolescentes que tiveram filho. A taxa de mortalidade materna é uma forma de avaliar a qualidade dos serviços de assistência reprodutiva, os quais refletem a influência da mulher na sociedade e o reconhecimento de suas necessidades. Segundo PNUD (2014), serviços ineficientes de saúde reprodutiva são um dos principais fatores de desigualdade de gênero em países em desenvolvimento. Além disso, elevadas taxas de mortalidade materna trazem implicações negativas, pois comprometem o desenvolvimento humano das crianças órfãs. Quanto à proporção de adolescentes que tiveram filho, trata-se de um indicador de desigualdade de gênero, pois a gravidez precoce traz consequências para a saúde das jovens e limita suas oportunidades, sendo por isso uma grande perda decorrente da desigualdade de gênero (PNUD, 2010).

A análise desses indicadores nas unidades federativas brasileiras, Tabela 6 , descreve uma situação favorável às mulheres em todas as unidades federativas, como também observado no Fórum Econômico Mundial (World Economic Forum, 2014) para o Brasil como um todo. 
Tabela 6. Indicadores do Índice Multidimensional de Desigualdade de Gênero (IMDG), dimensão saúde reprodutiva, por Unidade Federativa.

\begin{tabular}{|c|c|c|}
\hline Unidade Federativa & $\begin{array}{l}\text { Proporção de adolescentes } \\
\text { que tiveram filho }(\%)\end{array}$ & $\begin{array}{lr}\begin{array}{l}\text { Taxa de } \\
\text { materna/1000 }\end{array} & \text { nortalidade } \\
\text { vivos } & \text { nascidos }\end{array}$ \\
\hline Acre & 5,4 & 0,4 \\
\hline Amazonas & 5,1 & 0,9 \\
\hline Amapá & 5,0 & 0,2 \\
\hline Pará & 4,8 & 0,6 \\
\hline Rondônia & 3,9 & 0,6 \\
\hline Roraima & 5,0 & 0,1 \\
\hline Tocantins & 4,5 & 0,7 \\
\hline Alagoas & 4,1 & 0,6 \\
\hline Bahia & 3,4 & 0,8 \\
\hline Ceará & 3,2 & 0,7 \\
\hline Maranhão & 4,5 & 1,0 \\
\hline Paraíba & 3,4 & 0,5 \\
\hline Pernambuco & 3,6 & 0,5 \\
\hline Piauí & 3,7 & 0,9 \\
\hline Rio Grande do Norte & 3,4 & 0,3 \\
\hline Sergipe & 3,4 & 0,7 \\
\hline Distrito Federal & 2,7 & 0,4 \\
\hline Goiás & 3,2 & 0,6 \\
\hline Mato Grosso do Sul & 4,1 & 0,8 \\
\hline Mato Grosso & 3,9 & 0,7 \\
\hline Espírito Santo & 3,0 & 0,7 \\
\hline Minas Gerais & 2,6 & 0,5 \\
\hline Rio de Janeiro & 3,0 & 0,8 \\
\hline São Paulo & 2,7 & 0,4 \\
\hline Paraná & 3,2 & 0,6 \\
\hline Rio Grande do Sul & 2,6 & 0,6 \\
\hline Santa Catarina & 2,7 & 0,3 \\
\hline
\end{tabular}

Fonte: Elaborada pelos autores

Na Tabela 7 constam as razões Mulher/Homem referentes aos indicadores da dimensão "Fatores de Proteção". Nota-se a lacuna entre homens e mulheres no que diz respeito à proporção de pessoas de 10 anos ou mais de idade, ocupadas, que contribuem para instituto de previdência oficial no trabalho principal. A situação observada é decorrente do fato de parte significativa das mulheres ingressarem no mercado de trabalho de maneira informal (Farah, 2004). Esse cenário é observado 
em todas as unidades federativas e mostra a importância de políticas públicas que assegurem garantias trabalhistas às mulheres. Quanto ao indicador expectativa de vida, as mulheres encontram-se em situação mais favorável que os homens, também em todas as unidades federativas brasileiras.

Tabela 7. Razão Mulher/Homem dos indicadores adotados na construção do Índice Multidimensional de Desigualdade de Gênero (IMDG), dimensão Fatores de Proteção, por Unidade Federativa.

\begin{tabular}{|c|c|c|}
\hline Unidade Federativa & Esperança de vida ao nascer & $\begin{array}{l}\text { Proporção de pessoas de } 10 \\
\text { anos ou mais de idade } \\
\text { ocupadas, que contribuem } \\
\text { para instituto de previdência } \\
\text { oficial no trabalho principal }\end{array}$ \\
\hline Acre & 1,08 & 0,73 \\
\hline Amazonas & 1,09 & 0,69 \\
\hline Amapá & 1,12 & 0,74 \\
\hline Pará & 1,09 & 0,64 \\
\hline Rondônia & 1,08 & 0,66 \\
\hline Roraima & 1,07 & 0,87 \\
\hline Tocantins & 1,07 & 0,78 \\
\hline Alagoas & 1,13 & 0,53 \\
\hline Bahia & 1,09 & $\overline{0,76}$ \\
\hline Ceará & 1,13 & 0,78 \\
\hline Maranhão & 1,12 & 0,71 \\
\hline Paraíba & 1,11 & 0,75 \\
\hline Pernambuco & 1,11 & 0,65 \\
\hline Piauí & 1,09 & 0,72 \\
\hline Rio Grande do Norte & 1,11 & 0,71 \\
\hline Sergipe & 1,10 & 0,67 \\
\hline Distrito Federal & 1,10 & 0,84 \\
\hline Goiás & 1,09 & 0,72 \\
\hline Mato Grosso do Sul & 1,09 & 0,73 \\
\hline Mato Grosso & 1,10 & 0,65 \\
\hline Espírito Santo & 1,10 & 0,76 \\
\hline Minas Gerais & 1,10 & 0,74 \\
\hline Rio de Janeiro & 1,13 & 0,75 \\
\hline São Paulo & 1,12 & 0,74 \\
\hline Paraná & 1,09 & 0,74 \\
\hline Rio Grande do Sul & 1,10 & 0,81 \\
\hline Santa Catarina & 1,09 & 0,74 \\
\hline
\end{tabular}

R. Inter. Interdisc. INTERthesis, Florianópolis, v.12, n.1, p.292-320, Jan-Jun. 2015 
A análise das tabelas mostrou que as unidades federativas apresentam, em geral, os mesmos fatores de desigualdade de gênero, sendo os mais intensos verificados nos âmbitos político, doméstico e atividades econômicas. $O$ que as diferencia é a intensidade com que cada fator se manifesta, como verificado inicialmente pelo IMDG. Por exemplo, no caso do indicador proporção de pessoas de 10 anos ou mais de idade, ocupadas, que contribuem para instituto de previdência oficial no trabalho principal, a desigualdade verificada em Alagoas, ou seja, a razão Mulher/Homem, foi de 0,53, bem maior que a desigualdade em Roraima, cuja razão Mulher/Homem foi de 0,87. No entanto, as duas unidades federativas apresentam assimentrias quanto a esse indicador.

\section{CONSIDERAÇÕES FINAIS}

A hierarquização das unidades federativas brasileiras mostrou que não há um padrão regional quanto à desigualdade de gênero no Brasil, isto é, não há evidências que apontem uma região como mais desigual que outra. $O$ problema se distribui indistintamente no território nacional e se manifesta com níveis diferentes de intensidade nas unidades federativas.

No âmbito de interesse das políticas públicas, essa conclusão inicial poderia levar à suposição de que seriam necessárias intervenções espacialmente diferenciadas para a redução das desigualdades de gênero. No entanto, uma análise da razão mulher/homem dos indicadores selecionados no estudo, mostrou que os principais fatores determinantes da assimetria entre homens e mulheres são muito semelhantes entre as unidades federativas, ou seja, as prioridades são similares e requerem ações voltadas para o aumento da participação da mulher na política e no mercado de trabalho, além de equiparação de rendimentos médios e garantias trabalhistas. $O$ que as diferencia é a intensidade com que cada fator se manifesta em cada uma delas.

Uma análise integrada das dimensões mostra que as mulheres têm maior escolaridade que os homens, mas ainda têm menos chances de emprego formal, menores rendimentos médios e fraca participação na política. Esse é o padrão de desigualdade observado em todas as unidades federativas. 
Por fim, as prioridades identificadas no estudo são consistentes com as análises divulgadas em relatórios internacionais, as quais adotam uma escala nacional, o que mostra a adequação do índice adotado na pesquisa para captar a desigualdade e o colocam como uma ferramenta útil na elaboração de subsídios para políticas públicas nessa área. 
SPATIAL DISTRIBUTION OF GENDER INEQUALITY IN BRAZIL

\begin{abstract}
:
The purpose of this article was to analyze how gender inequality is distributed all over the Brazil. To that end, it has been built the Multidimensional Gender Inequality Index (MGII), a synthetic index. The main findings underlined that inequality between men and women manifests itself at different degrees in the federal units, but it is determined by a variety of common factors. The asymmetries are observed, mainly, in the political, labor and income dimensions.
\end{abstract}

Keywords: Synthetic index. Gender inequality. Multidimensional analysis. Federal units. Public policies.

\title{
DISTRIBUCIÓN ESPACIAL DE LA DESIGUALDAD DE GÉNERO EN BRASIL
}

\section{Resumen:}

El artículo pretende analizar cómo la desigualdad de género se distribuye entre las unidades federales de Brasil. Para ello, se optó por elaborar un índice sintético llamado Índice Multidimensional de Desigualdad de Género (IMDG). Los principales resultados muestran que la desigualdad entre hombres y mujeres se manifiesta con diferentes grados en las unidades federativas, pero es determinada por factores comunes. Las diferencias más notables residen en las dimensiones política, trabajo e ingresos.

Palabras-clave: Desigualdad de género. Índice sintético. Análisis multidimensional. Unidades federales. Políticas públicas. 


\section{REFERÊNCIAS}

ALVES, José Eustáquio Diniz. Comentários sobre o Ranking de Desigualdade de Gênero elaborado pelo Fórum Econômico Mundial . Boletim do Observatório Brasil da Igualdade de Gênero - novembro/2011. Disponível em: http://www.observatoriodegenero.gov.br/menu/noticias/opiniao-comentarios-sobre-oranking-de-desigualdade-de-genero-elaborado-pelo-forum-economico-mundial/ . Acesso em 13 fev.2015.

ALVES, José Eustáquio Diniz. CORREA, Sônia. Igualdade e desigualdade de gênero no Brasil: um panorama preliminar, 15 anos depois do Cairo. Seminário Brasil, 15 anos após a Conferência do Cairo. ABEP. Belo Horizonte, MG. 2009. BÉRENGER, Valérie, VERDIER-CHOUCHANE, Audrey. 2007. "Multidimensional Measures of Well-Being: Standard of Living and Quality of Life Across Countries." World Development 35(7): 1259-76. 2007.

BÖHRINGER, Christoph; JOCHEM, Patrick EP. Measuring the immeasurable-A survey of sustainability indices. Ecological economics, v. 63, n. 1, p. 1-8, 2007.

BOOYSEN, Frederik. "AND EVALUATION OF COMPOSITE AN OVERVIEW INDICES." Social Indicators Research 59(2): 115-51. 2002. Disponível em: http://www.jstor.org/stable/27527024. Acesso em 16 mar. 2015.

BRASIL. Lei 9.100 de 29 de setembro de 1995. Estabelece normas para a realização das eleições municipais de 3 de outubro de 1996, e dá outras providências. Disponível em: http://www.planalto.gov.br/ccivil 03/leis/L9100.htm . Acesso em 24. Fev. 2015.

BRUSCHINI, Maria Cristina Aranha. Trabalho e gênero no Brasil nos últimos dez anos. Cadernos de Pesquisa, v. 37, n. 132, p. 537-572, 2007.

CEDIM - Conselho Estadual dos Direitos da Mulher. A Mulher e o Poder Legislativo no Estado do Rio de Janeiro: Lugares, Perfis e Experiências Municipais. Cadernos do CEDIM n ${ }^{\circ}$ 2, série Pesquisa. Ed. CEDIM-RJ. Rio de Janeiro. 2002.

COSTA, Ana Alice Alcântara. "Trajetória e perspectivas do feminismo para o próximo milênio". In: PASSOS, Elizete; ALVES, Ívia; MACEDO, Márcia. Metamorfoses: gênero nas perspectivas interdisciplinares. Salvador: UFBA, Núcleo de Estudos Interdisciplinares sobre a Mulher, 1998. p. 25-37. 
FARAH, Marta Ferreira Santos. Gênero e políticas públicas. Estudos Feministas, v. 12, n. 1, p. 47-71, 2004.

FERRANT, G. O Índice de Gênero Desigualdades (GII), como uma nova forma de medir as desigualdades de gênero nos países em desenvolvimento, Sciences. New York, pp.106-112. 2010.

FREUDENBERG, Michael. Composite Indicators of Country Performance. OECD. Paris. 2003.

GOLDANI, Ana Maria. Famílias e gêneros: uma proposta para avaliar (des) igualdades. Anais do XII Encontro Nacional de Estudos Populacionais, 2000.

HILL, M. Anne; KING, Elizabeth. Women's education and economic well-being. Feminist Economics, v. 1, n. 2, p. 21-46, 1995.

JACOBS, Rowena, GODDARD, Maria. "How Do Performance Indicators Add Up? An Examination of Composite Indicators in Public Services." Public Money \& Management's (April): 103-10. 2007.

KLASEN, Stephan; SCHÜLER, Dana. Reforming the gender-related development index and the gender empowerment measure: Implementing some specific proposals. Feminist Economics, v. 17, n. 1, p. 1-30, 2011.

MAINALI, Brijesh et al. Assessing rural energy sustainability in developing countries. Energy for Sustainable Development, v. 19, p. 15-28, 2014.

MIGUEL. Luís Felipe. Teoria política feminista e liberalismo: o caso das cotas de representação. Revista Brasileira de Ciências Sociais, São Paulo, v. 15, n. 44, p. 91-102, out, 2000.

MOSANER, Marcelo Amado Sette; DOWBOR, Ladislau. A dimensão política de índices sintéticos de desenvolvimento e a posição relativa dos Estados Unidos. Pesquisa \& Debate. Revista do Programa de Estudos Pós-Graduados em Economia Política. ISSN 1806-9029, v. 25, n. 2 (46), 2014. 
NARDO, Michela et al. "Handbook on Constructing Composite Indicators METHODOLOGY AND USER GUIDE. 2005.

PERMANYER, I. Are UNDP Indices Appropriate to Capture Gender Inequalities in Europe? Soc Indic Res. 1-24. 2011.

PINHEIRO, R. S., VIACAVA, F., TRAVASSOS, C., BRITO, A. D. S. (2002). Gênero, morbidade, acesso e utilização de serviços de saúde no Brasil. Ciência \& Saúde Coletiva, 7(4), 687-707.

PIOVESAN. Flávia. Direitos humanos, Civis e políticos: A conquista da Cidadania feminina, In O Progresso das Mulheres no Brasil 2003-2010. BARSTED, Leila Linhares; PITANGUY, Jacqueline (organizadoras), Rio de Janeiro: CEPIA; Brasília: ONU Mulheres, 2011. 436p.

PNUD - Programa de Desenvolvimento das Nações Unidas. Relatório de Desenvolvimento Humano de 2010: A verdadeira riqueza das nações. United Nations Development Programme New York: United Nations Development Programme.2010.

PNUD - Programa de Desenvolvimento das Nações Unidas. Sustainability and Equity: A Better Future for All. United Nations Development Programme. New York. United Nations Development Programme.2011.

PNUD - Programa de Desenvolvimento das Nações Unidas. Sustaining Human Progress: Reducing Vulnerabilities and Building Resilience. United Nations Development Programme. New York. United Nations Development Programme., 2014.

RIGBY, Dan; WOODHOUSE, Phil; YOUNG, Trevor; BURTON, Michael. "Constructing a Farm Level Indicator of Sustainable Agricultural Practice." Ecological Economics 39(3): 463-78. 2001.

SAFFIOTI, H. I. B. Gênero, patriarcado, violência. São Paulo,SP: Editora da Fundação Perseu Abramo. 2004.

VAZ, Gislene de Almeida. A participação da mulher na política brasileira: a lei de cotas. 66f. Monografia (Curso de Especialização em Processo Legislativo), Centro de Formação e Treinamento e Aperfeiçoamento da Câmara dos Deputados, Brasília, 2008 
VIANNA, Claudia Pereira; UNBEHAUM, Sandra. O gênero nas políticas públicas de educação no Brasil: 1988-2002. Cadernos de Pesquisa, v. 34, n. 121, p. 77-104, 2004.

WORLD ECONOMIC FORUM. The Global Gender Gap Report 2011. Geneva, Switzerland 2011. Disponível em: http://www3.weforum.org/docs/WEF GenderGap Report 2011.pdf . Acesso em: 13.fev.2015.

WORLD ECONOMIC FORUM. The Global Gender Gap Report 2014. Geneva, Switzerland 2014. Disponível em:

http://www3.weforum.org/docs/GGGR14/GGGR CompleteReport 2014.pdf Acesso em 24.fev.2015.

Artigo:

Submetido em 26.08.2014

Aceito em 24.03.2015 